\title{
Demonstration of Improved Heteroepitaxy, Scaled Gate Stack and Reduced Interface States Enabling Heterojunction Tunnel FETs with High Drive Current and High On-Off Ratio
}

D. K. Mohata, R. Bijesh, Y. Zhu ${ }^{1}$, M. K. Hudait ${ }^{1}$, R. Southwick ${ }^{2}$, Z. Chbili ${ }^{2}$, D. Gundlach ${ }^{2}$, J. Suehle ${ }^{2}$,

\author{
J. M. Fastenau ${ }^{3}$, D. Loubychev ${ }^{3}$, A. K. Liu ${ }^{3}$, T. S. Mayer, V. Narayanan and S. Datta
}

Electrical Engineering, The Pennsylvania State University, PA; ${ }^{1}$ Electrical and Computer Engineering, Virginia Tech, VA;

${ }^{2}$ National Institute of Standards and Technology, MD; ${ }^{3}$ IQE Inc., Bethlehem, PA,USA; Email: dkm154@psu.edu

Abstract: Staggered tunnel junction $\left(\mathrm{GaAs}_{0.35} \mathrm{Sb}_{0.65}\right.$ $\left./ \mathrm{In}_{0.7} \mathrm{Ga}_{0.3} \mathrm{As}\right)$ is used to demonstrate heterojunction tunnel FET (TFET) with the highest drive current, $\mathrm{I}_{\text {on }}$, of $135 \mu \mathrm{A} / \mu \mathrm{m}$ and highest $\mathrm{I}_{\mathrm{on}} / \mathrm{I}_{\text {off }}$ ratio of $2.7 \times 10^{4}\left(\mathrm{~V}_{\mathrm{ds}}=0.5 \mathrm{~V}\right.$, $\mathrm{V}_{\text {on }}-\mathrm{V}_{\text {off }}=1.5 \mathrm{~V}$ ). Effective oxide thickness (EOT) scaling (using $\mathrm{Al}_{2} \mathrm{O}_{3} / \mathrm{HfO}_{2}$ bilayer gate stack) coupled with pulsed $\mathrm{I}-\mathrm{V}$ measurements (suppressing $\mathrm{D}_{\mathrm{it}}$ response) enable demonstration of steeper switching TFET.

Introduction: Mixed arsenide-antimonide based lattice-matched heterojunction provides a wide range of compositionally tunable effective tunneling barrier height $\left(\mathrm{Eb}_{\text {eff }}\right)$, from $0.5 \mathrm{eV}$ to $0 \mathrm{eV}[4,7]$. With increasing $\mathrm{Sb}$ and $\mathrm{As}$ composition, $\mathrm{Eb}_{\text {eff }}$ reduces and TFET $\mathrm{I}_{\text {on }}$ can approach MOSFET level without compromising the high $\mathrm{I}_{\text {on }} / \mathrm{I}_{\text {off }}$ ratio [3-5]. However, engineering an abrupt change from $\mathrm{Sb}$ rich to As rich interface is a significant growth challenge [3]. The objectives of this work are three fold: 1) we explore proper growth switching conditions to control the atomic termination at the $\mathrm{GaAs}_{0.35} \mathrm{Sb}_{0.65} / \mathrm{In}_{0.7} \mathrm{Ga}_{0.3}$ As interface to reduce defects and demonstrate TFET with higher $\mathrm{I}_{\mathrm{on}} / \mathrm{I}_{\text {off }}$ ratio than reported before [3];2) we demonstrate the effect of EOT scaling on TFET switching slope (SS) enhancement; 3) finally, we employ ultra-fast pulsed I-V measurement to mitigate the interface state $\left(D_{i t}\right)$ response in order to improve the TFET SS and $\mathrm{I}_{\text {on }} / \mathrm{I}_{\text {off }}$ ratio over a specified gate voltage $\left(\mathrm{V}_{\mathrm{gs}}\right)$ swing.

Materials Characterization: Figs. 1(a-c) show the schematic layer structures for $\operatorname{In}_{0.7} \mathrm{Ga}_{0.3}$ As HomJ, as well as $\mathrm{GaAs}_{1-\mathrm{x}} \mathrm{Sb}_{\mathrm{x}} / \mathrm{In}_{\mathrm{y}} \mathrm{Ga}_{1-\mathrm{y}} \mathrm{As}$ Moderate and High HetJ TFETs for $\mathrm{x}=0.6,0.65$ and $\mathrm{y}=0.65,0.7$ respectively, grown on semi-insulating InP substrate using solid-source molecular beam epitaxy. For the High HetJ TFET structure, two wafers were grown to study the impact of (a) GaAs-like and (b) InAs-like surface termination while switching from Sb-rich $\mathrm{GaAs}_{0.35} \mathrm{Sb}_{0.65}$ to As-rich $\mathrm{In}_{0.7} \mathrm{Ga}_{0.3}$ As layer. For the latter case, while ramping up the As flux from $35 \%$ to $100 \%, 1-2 \mathrm{ML}$ of Indium (In) was added prior to $\mathrm{In}_{0.7} \mathrm{Ga}_{0.3}$ As layer. Figs. 2 (a,b) show asymmetric (115) reciprocal space maps of the High HetJ TFET structures. In both cases, the growth of the metamorphic buffer results in an $\operatorname{In}_{0.65} \mathrm{Al}_{0.35} \mathrm{As}$ "virtual" substrate with $\geq 90 \%$ strain relaxation. However, the subsequent $\mathrm{GaAs}_{0.35} \mathrm{Sb}_{0.65}$ and $\mathrm{In}_{0.7} \mathrm{Ga}_{0.3}$ As active device layers differ in their strain with respect to the "virtual" substrate. With the GaAs terminated heterointerface, the active layers are strain relaxed and susceptible to defect formation, whereas the device layers on the InAs terminated interface are pseudomorphic to the $\mathrm{In}_{0.65} \mathrm{Al}_{0.35} \mathrm{As}$ "virtual substrate" and likely "defect-free". This is evident in Fig. 2 (c,d) where atomic force microscopy (AFM) images reveal lower surface roughness $(4.5 \mathrm{~nm})$ and $2 \mathrm{D}$ cross-hatch pattern for InAs terminated wafer compared to the GaAs terminated one (with roughness of $5.6 \mathrm{~nm}$ and no cross-hatch pattern).

Device Characterization: The vertical TFET fabrication process is described in [4]. Fig. 1(d) shows the cross-sectional TEM micrograph of the fabricated High Hetj TFET. Figs. 2 (e,f) compare the $\mathrm{I}_{\mathrm{ds}}-\mathrm{V}_{\mathrm{gs}}$ and $\mathrm{I}_{\mathrm{ds}}-\mathrm{V}_{\mathrm{ds}}$ characteristics for the high HetJ TFET with GaAs and InAs surface termination. More than 3 orders in magnitude improvement in $\mathrm{I}_{\mathrm{on}} / \mathrm{I}_{\mathrm{off}}$ ratio is achieved with the latter due to the reduction in defect assisted conduction. The improvement in heteroepitaxy with InAs termination is reflected in the improved electrostatics (smaller SS and DIBT) for the same device geometry. Figs. 1(e-i) compare the performance of the High HetJ TFET with Mod. HetJ and HomJ TFETs. First, $I_{\text {on }}$ progressively increases by $325 \%$ with decreasing $\mathrm{Eb}_{\text {eff }}$ (from $0.58 \mathrm{eV}$ to $0.25 \mathrm{eV}$ ) due to the increase in tunneling transmission coefficient. Second, the drain induced barrier thinning (DIBT) improves with reducing $E b_{\text {eff }}$ due to inter-band generation occurring closer to the source/channel junction, thus improving device electrostatics [5]. The SS vs $I_{d s}$ curve also shifts with reducing $E b_{\text {eff }}$, with the minimum SS occurring at higher $\mathrm{I}_{\mathrm{ds}}$ which is essential for TFET operation with MOSFET like performance. To further enhance performance, we scaled the EOT for the High HetJ TFET, from $2 \mathrm{~nm}$ to $1.75 \mathrm{~nm}$, and reduced the $\mathrm{V}_{\mathrm{gs}}$ window by $0.5 \mathrm{~V}$ for the same $\mathrm{I}_{\text {on }}-\mathrm{I}_{\text {off }}$ (Fig. 3a). Figs. 3(b,c) summarize the improvement in both $I_{\text {on }}$ (tunneling transmission) and DIBT (electrostatics) as a function of $\mathrm{Eb}_{\text {eff }}$ and EOT. The switching slope, $\mathrm{SS}$, in all fabricated devices is greater than $60 \mathrm{mV} / \mathrm{dec}$ at room temperature and is caused by the presence of interface states $\left(D_{i t}\right)$ at the high- $/ /$ channel interface $[1,3-5]$. We perform ultra-fast pulsed $\mathrm{I}_{\mathrm{ds}}-\mathrm{V}_{\mathrm{gs}}$ measurements on the HomJ TFET with input gate voltage pulses having rise time $\left(t_{r}\right)$ of $10 \mathrm{~ns}$, to suppress $\mathrm{D}_{\mathrm{it}}$ response. The TFET $\mathrm{I}_{\mathrm{ds}}$ response was then reliably sampled after $150 \mathrm{~ns}\left(\mathrm{t}_{\text {meas }}\right)$. The pulsed $\mathrm{I}_{\mathrm{ds}}-\mathrm{V}_{\mathrm{gs}}$ measurement (Figs. 4(a,b)) show marked steepening of the switching slope (SS) with minimum SS of $100 \mathrm{mV} /$ decade and matches the theoretical $\mathrm{I}_{\mathrm{ds}}-\mathrm{V}_{\mathrm{gs}}$ for $\mathrm{D}_{\mathrm{it}} \sim 8 \times 10^{11} / \mathrm{cm}^{2}$ [7]. The pulsed $\mathrm{I}_{\mathrm{ds}}-\mathrm{V}_{\mathrm{gs}}$ study allows us to accurately predict the performance realizable in High HetJ TFET with similar $D_{i t}$ $\sim 8 \times 10^{11} / \mathrm{cm}^{2}$ and EOT of $1 \mathrm{~nm}$ (Figs. 5(a,b)). Two dimensional device simulations show that high Hetj TFET can maintain sub $\mathrm{kT} / \mathrm{q}$ SS over two orders of magnitude of drain current $\left(10^{-9}\right.$ to $\left.10^{-7} \mathrm{~A} / \mu \mathrm{m}\right)$. Heterojunction Tunnel FET can deliver MOSFET-like performance with better $\mathrm{I}_{\mathrm{on}} / \mathrm{I}_{\text {off }}$, making them a promising post CMOS candidate for low power, high performance applications.

Summary: Table 1 benchmarks the on current $\left(\mathrm{I}_{\text {on }}\right)$, on-off ratio $\left(\mathrm{I}_{\text {on }} / \mathrm{I}_{\text {off }}\right)$ and effective switching slope $\left(\mathrm{SS}_{\text {eff }}\right)$ of TFETs, demonstrated till date. The High HetJ TFET in this work shows $\mathrm{I}_{\text {on }}$ of $135 \mu \mathrm{A} / \mu \mathrm{m}$ and $\mathrm{I}_{\text {on }} / \mathrm{I}_{\text {off }}>10^{4}$ at $\mathrm{V}_{\mathrm{ds}}=0.5 \mathrm{~V}$ and $\mathrm{V}_{\text {on }}-\mathrm{V}_{\text {off }}=1.5 \mathrm{~V}$. This is the highest ever reported $\mathrm{I}_{\text {on }} / \mathrm{I}_{\text {off }}$ ratio for $\mathrm{I}_{\text {on }}>100 \mu \mathrm{A} / \mu \mathrm{m}$ in the category of TFETs.

Acknowledgement: We acknowledge financial support from Intel Corp, IBM PhD Fellowship (Mohata) and NRI/SRC sponsored MIND center. References

[1] Zhao et. al, EDL, 2011

[3] Mohata et. al, IEDM 2011

[5] Mohata et. al, APEX, 2011
[2] Dewey et. al, IEDM, 2011

[4 ]Mohata et. al, DRC, 2011

[6]Seabaugh et. al, IEEE Proc.,2010 
Fabrication and Electrical Characterization

(a)HomJ TFET

\begin{tabular}{|c|}
\hline $\begin{array}{c}200 \mathrm{~nm}-\mathrm{In}_{0.7} \mathrm{Ga}_{0.3} \mathrm{As} \\
(\mathrm{N}+) \mathrm{Si}-1 \times 10^{18} / \mathrm{cm}^{3}\end{array}$ \\
\hline $\begin{array}{c}150 \mathrm{~nm}-\mathrm{In}_{0.7} \mathrm{Ga}_{0.3} \mathrm{As} \\
\text { intrinsic }\end{array}$ \\
\hline $10 \mathrm{~nm}-\mathrm{In}_{0.7} \mathrm{Ga}_{0.3} \mathrm{As}$ \\
$(\mathrm{P}++) \mathrm{C}-\left(10^{20} / \mathrm{cm}^{3}\right)$ \\
\hline $300 \mathrm{~nm}-\mathrm{In}_{0.7} \mathrm{Ga}_{0.3} \mathrm{As}$ \\
$(\mathrm{P}+) \mathrm{C}-\left(5 \times 10^{19} / \mathrm{cm}^{3}\right)$ \\
\hline $100 \mathrm{~nm} \mathrm{Al}_{0.3} \mathrm{In}_{0.7} \mathrm{As}$ buffer \\
\hline Linearly graded relaxed buffer \\
$1000 \mathrm{~nm} \mathrm{Al}_{1 .-\mathrm{x}} \mathrm{In}_{\mathrm{x}} \mathrm{As}$ \\
$(\mathrm{x}->0.52$ to 0.7$)$ \\
\hline InP Substrate \\
\hline
\end{tabular}

(b) Moderate HetJ TFET

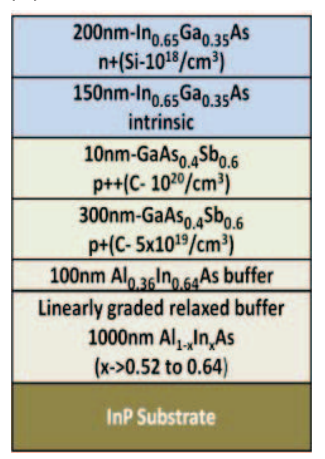

(c) High HetJ TFET
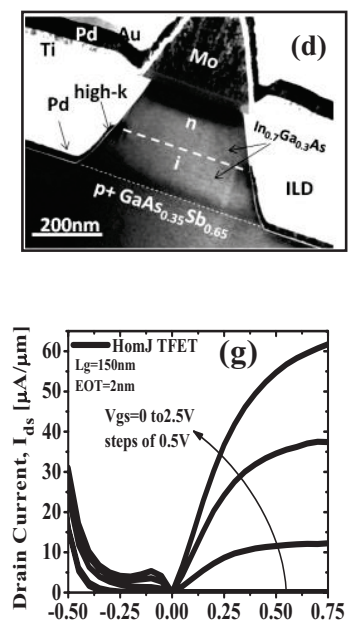

Drain Voltage, $\mathrm{V}_{\mathrm{ds}}[\mathrm{V}]$

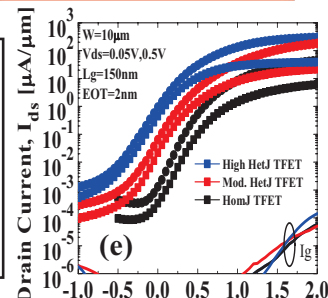

Gate Voltage, $\mathrm{V}_{\mathrm{gs}}[\mathrm{V}$
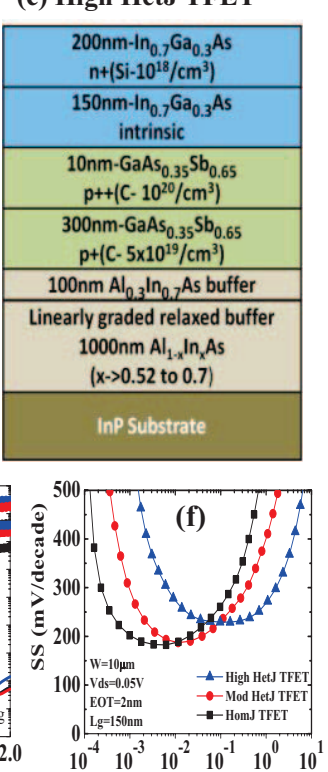

Drain Current, $\mathrm{I}_{\mathrm{ds}}[\mu \mathrm{A} / \mu \mathrm{m}]$

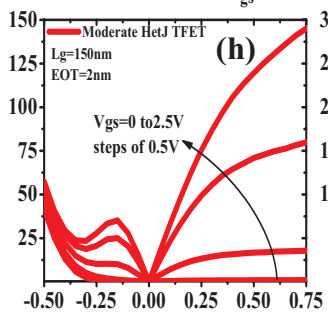

Drain Voltage, $\mathrm{V}_{\mathrm{ds}}[\mathrm{V}]$

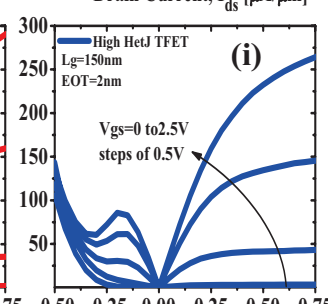

Drain Voltage, $\mathrm{V}_{\mathrm{ds}}[\mathrm{V}]$

Figure 1-(a-c) TFET layer structures. (d) High HetJ TFET cross-section TEM micrograph. (e-i) Measured $\mathrm{I}_{\mathrm{ds}}-\mathrm{V}_{\mathrm{gs}}, \mathrm{I}_{\mathrm{ds}}-\mathrm{V}_{\mathrm{ds}}$ and extracted switching slope (SS) vs $\mathrm{I}_{\mathrm{ds}}$ characteristics for the three fabricated devices.

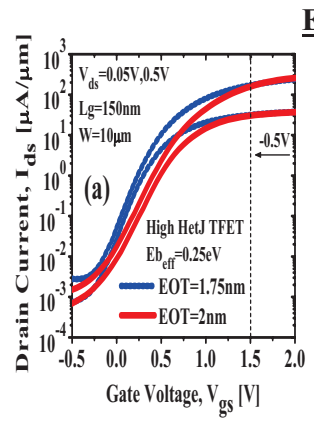

EOT scaling (Experimental)
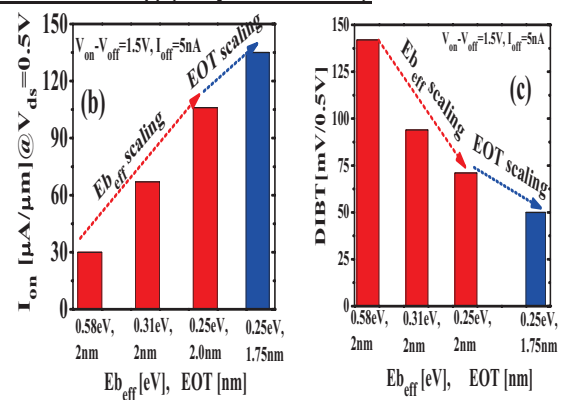

Figure 3-(a) Improved $\mathrm{I}_{\mathrm{ds}}-\mathrm{V}_{\mathrm{gs}}$ characteristics of the high HetJ TFET with EOT scaling. $(\mathbf{b}, \mathbf{c})$ Summary of improvement in measured $\mathrm{I}_{\mathrm{O}}$ and Drain Induced Barrier Thinning (DIBT) with $\mathrm{Eb}_{\text {eff }}$ and EOT scaling. DIBT improves with increasing stagger due to interband generation occurring closer to the source-channel interface [5].

Further EOT scaling in high HetJ TFET (Exp., Model \& Projection)

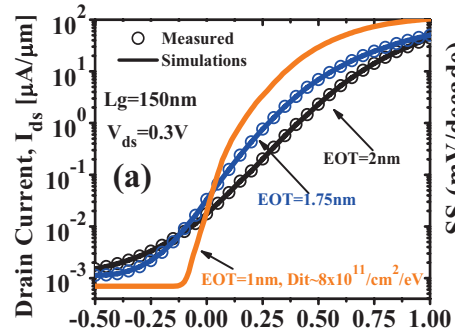

Gate Voltage, $V_{\text {gs }}[\mathrm{V}]$

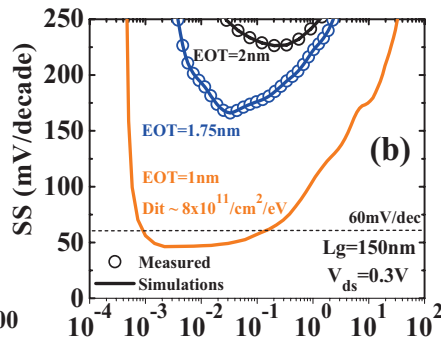

Drain Current, $I_{d s}[\mu \mathrm{A} / \mu \mathrm{m}]$

Figure 5-(a,b) An improvement in high-k/channel interface $\left(D_{i t}\right.$ $\sim 8 \times 10^{11} / \mathrm{cm}^{2} / \mathrm{eV}$ ) combined with further EOT scaling would enable MOSFET-like TFET operation at low $\mathrm{V}_{\mathrm{cc}}$ with higher $\mathrm{I}_{\mathrm{on}} / \mathrm{I}_{\mathrm{off}}$ ratio.

\section{Materials Growth Improvement}

(a)GaAs terminated

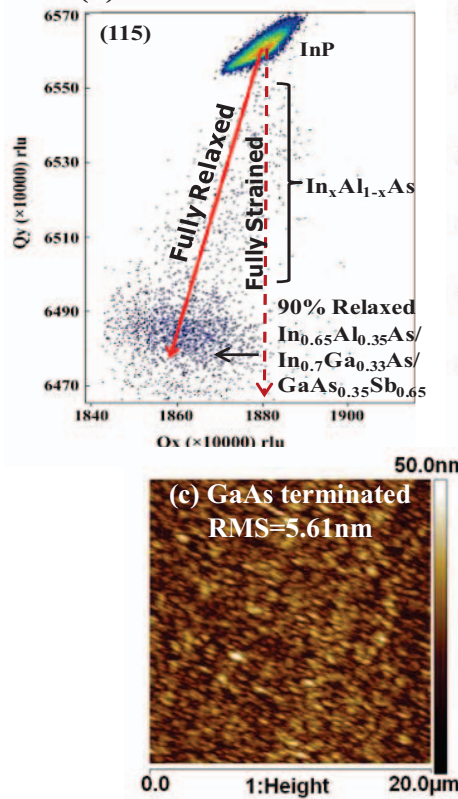

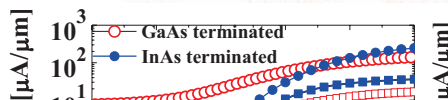

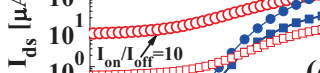

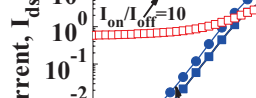

$\begin{array}{ll}10^{-1} & \\ 10^{-2} & \mathrm{~W}=10 \mu \mathrm{m} \\ \mathrm{V} & \mathrm{ds}=0.05 \mathrm{~V}\end{array}$

$10^{-3} \log _{\mathrm{I}_{\text {on }} / \mathrm{I} \text { off }}>10^{4} \quad \mathrm{Lg}=150 \mathrm{~nm}$

$\begin{array}{ccccccc}10 & -0.5 & 0.0 & 0.5 & 1.0 & 1.5 & 2.0\end{array}$

$\mathrm{V}_{\mathrm{gs}}-\mathrm{V}_{\text {off }}[\mathrm{V}]$

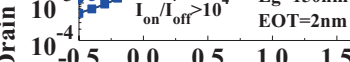

(b)InAs terminated
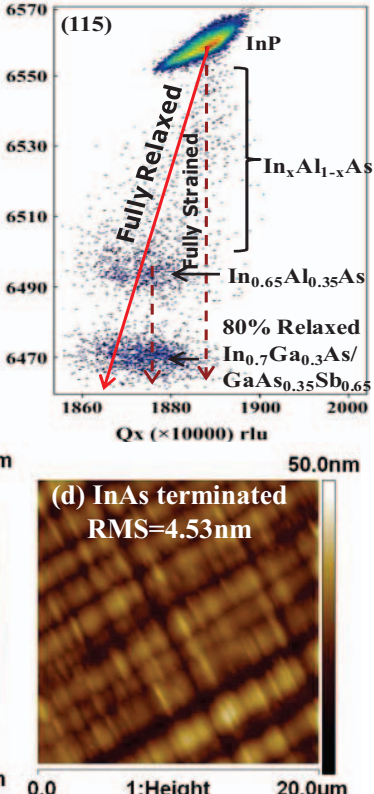

Figure 2- (a,b) Asymmetric (115) reciprocal space map and (c,d) $20 \times 20 \mu \mathrm{m}^{2}$ atomic force microscopy image of High HetJ TFET layers for the cases with GaAs and InAs terminated hetero-interfaces; (e,f) Improvement in $\mathrm{Ids}_{\mathrm{ds}} \mathrm{V}_{\mathrm{gs}}$ and $\mathrm{I}_{\mathrm{ds}}-\mathrm{V}_{\mathrm{ds}}$ characteristics with InAs terminated hetero-interface.

Minimizing Dit response using Fast I-V (HomJ TFET)
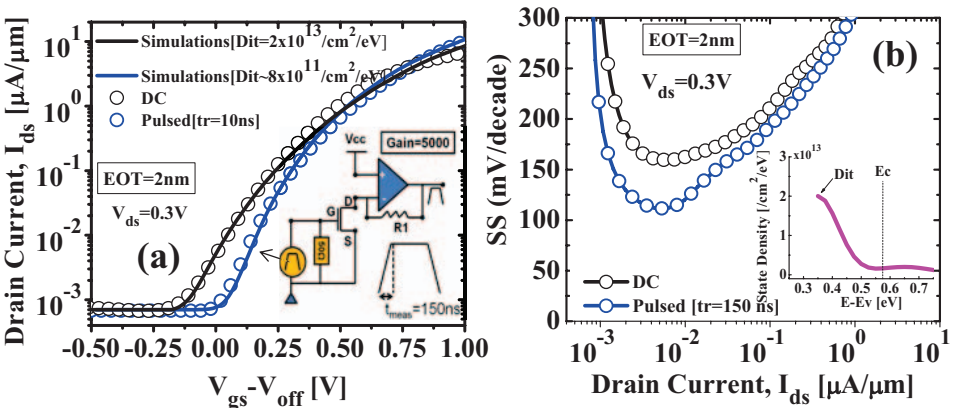

Figure 4-(a) Pulsed $\mathrm{I}_{\mathrm{ds}}-\mathrm{V}_{\mathrm{gs}}$ measured on HomJ TFET showing steeper switching by avoiding slow $\mathrm{D}_{\text {it }}$ response. Inset shows simplified pulsed I-V set-up. (b) SS vs $\mathrm{I}_{\mathrm{ds}}$ showing improved SS minimum with pulsing. Inset shows $\mathrm{D}_{\text {it }}$ profile used to model DC and pulsed $\mathrm{I}_{\mathrm{ds}}-\mathrm{V}_{\mathrm{gs}}$ measurements.

\begin{tabular}{|ccccccccc|}
\hline Reference & $\begin{array}{c}\mathrm{Eb}_{\text {eff }} \\
(\mathrm{eV})\end{array}$ & $\begin{array}{c}\mathrm{Lg} \\
(\mathrm{nm})\end{array}$ & $\begin{array}{c}\mathrm{EOT} \\
(\mathrm{nm})\end{array}$ & $\begin{array}{c}\mathrm{V}_{\text {on }}-\mathrm{V}_{\text {off }} \\
(\mathrm{V})\end{array}$ & $\begin{array}{c}\mathrm{Vds} \\
(\mathrm{V})\end{array}$ & $\begin{array}{c}\text { lon } \\
(\mu \mathrm{A} / \mu \mathrm{m})\end{array}$ & $\begin{array}{c}\text { lon/ } \\
\text { loff }\end{array}$ & $\begin{array}{c}\mathrm{SS}_{\text {eff }} \\
(\mathrm{mV} / \mathrm{dec})\end{array}$ \\
\hline $\begin{array}{c}\text { Zhao et. al, } \\
\text { EDL,2011 [1] }\end{array}$ & 0.58 & 100 & 1.2 & 1.5 & 0.5 & 30 & $6 \times 10^{3}$ & 200 \\
\hline $\begin{array}{c}\text { Dewey et. al } \\
\text { IEDM, 2011 [2] }\end{array}$ & 0.74 & 100 & 1.1 & 0.9 & 0.3 & 8 & $1.6 \times 10^{3}$ & 140 \\
\hline $\begin{array}{c}\text { Dewey et. al } \\
\text { IEDM,2011 [2] }\end{array}$ & 0.58 & 100 & 1.1 & 0.9 & 0.3 & 17 & $3.4 \times 10^{3}$ & 106 \\
\hline $\begin{array}{c}\text { Mohata et. al } \\
\text { IEDM, 2011 [3] }\end{array}$ & 0.25 & 150 & 2 & 1.5 & 0.5 & 135 & 10 & 750 \\
\hline $\begin{array}{c}\text { HomJ } \\
\text { (This work) }\end{array}$ & 0.58 & 150 & 2 & 1.5 & 0.5 & 30 & $6 \times 10^{3}$ & 200 \\
\hline $\begin{array}{c}\text { Mod. Het] } \\
\text { (This work) }\end{array}$ & 0.31 & 150 & 1.75 & 1.5 & 0.5 & 78 & $1.5 \times 10^{4}$ & 179 \\
\hline $\begin{array}{c}\text { High HetJ } \\
\text { (This work) }\end{array}$ & 0.25 & 150 & 1.75 & 1.5 & 0.5 & 135 & $2.7 \times 10^{4}$ & 169 \\
\hline
\end{tabular}

Table 1- Benchmarking $\mathrm{I}_{\text {on }}$ and $\mathrm{I}_{\text {on }} / \mathrm{I}_{\text {off }}$ at $\mathrm{V}_{\mathrm{ds}}=0.5 \mathrm{~V}, \mathrm{I}_{\text {off }}=5 \mathrm{nA} / \mu \mathrm{m}$ [ITRS-2010], where $\mathrm{SS}_{\text {eff }}=\left(\mathrm{V}_{\text {on }}-\mathrm{V}_{\text {off }}\right) /\left[2 \log \left(\mathrm{I}_{\text {on }} / \mathrm{I}_{\text {off }}\right)\right][6]$ 